\title{
Efficient C3-alkylsulfenylation of indoles under mild conditions using Lewis acid- activated 8-quinolinethiosulfonates.
}

\author{
Erwan Galardon ${ }^{\mathrm{a}}$ \\ a UMR 8601, LCBPT, CNRS-Université de Paris, 45 rue des Sts Pères, 75006 Paris, France. E-mail: erwan.galardon@parisdescartes.fr
}

The importance of sulfur-containing compounds in various fields, ranging from material science ${ }^{[1]}$ to medicinal chemistry, ${ }^{[2]}$ has called for the development of various synthetic strategies to form carbon-sulfur (C-S) bonds. Thus, numerous approaches based on the nucleophilicity of thiols have been designed over the years, which mostly use air-sensitive noble metal catalysts. ${ }^{[3]}$ At the opposite, the use of electrophilic sulfur reagents is also a powerful, more eco-friendly approach, in particular for the sulfenylation of C-H bonds into C-S bonds. ${ }^{[4]}$ In this context, the sulfenylation of indoles (Equation 1) has become a benchmark reaction to develop and test new sulfenyl transfer reagents, because indoles are good nucleophiles and their occurrence in many natural products or biological active compounds makes them attractive synthetic targets. ${ }^{[5]}$.<smiles></smiles>

For instance, metal-catalyzed or metal-free protocols have been reported, in which disulfides, sulfinic acid and their salts, sulfonyl chlorides, sulfonylhydrazine, or N-thiophtalimides are used as source of electrophilic sulfur. ${ }^{\text {[4a, }}$ 6] Thiosulfonates $\left(\mathrm{RSO}_{2} \mathrm{SR}^{\prime}\right)$ are another class of recently reviewed ${ }^{[7]}$ reagents, which were also studied for C-S bond formation ${ }^{[\underline{[}]}$ and for indole sulfenylation. ${ }^{[9]}$ However, despite this large pool of sulfenylation agents, the difficult activation of the chalcogen centre essentially limits these reagents to the formation of C-S(aryl) bonds. On the other hand, the transfer of alkylsulfenyl groups is more difficult and often requires harsh activating conditions (Table 1).

Scheme 1. Sulfenylating agents $\mathbf{Q S O}_{2} \mathbf{S R}$ used in this study

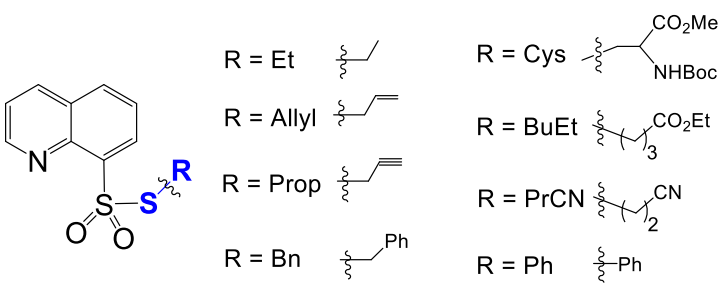

Thus, most protocols require heating or microwave activation, ${ }^{[6 a, 9-10]}$ and to my knowledge only a brief report of alkylsulfenylation of indole at room temperature was published ${ }^{[11]}$ Here, we propose an original approach based on new quinoline-containing thiosulfonates $\left(\mathbf{Q S O}_{2} \mathbf{S R}\right.$, Scheme 1) to efficiently transfer alkylsulfenyl groups to indoles under mild conditions. Coordination of a Lewis acid to the quinoline nitrogen indeed enhances the electrophilicity of the sulfur compared to standard thiosulfonates. 
Table 1. Typical protocols for the C3-alkylsulfenylation of indoles

\begin{tabular}{|c|c|c|}
\hline Donor & Experimental Conditions & Alkyl groups \\
\hline Phtal-SR & 0.9 indole, $0.5 \% \mathrm{MgBr}_{2}, \mathrm{DMAc}, 90^{\circ} \mathrm{C}^{[6 \mathrm{a}]}$ & $\mathrm{Me}$, ,Et, cHex, iPr \\
\hline MBT-SR & 0.9 indole, $10 \%$ CuI, DMSO, $\mathrm{rt}^{[11]}$ & Et, $\mathrm{Bz}$ \\
\hline $\mathrm{RSO}_{2} \mathrm{Cl}$ & $\begin{array}{c}2 \text { indole, } 10 \% \mathrm{I}_{2}, 80^{\circ} \mathrm{C}, 1,4 \text {-dioxane } \\
0.5 \text { indole, } 1.5 \mathrm{TBAI}, 60^{\circ} \mathrm{C}, \mathrm{DMF}^{[10 \mathrm{~b}]}\end{array}$ & $\begin{array}{l}\text { Me, } \mathrm{Bn}, n-\mathrm{Bu} \\
\quad \mathrm{Et}, i \text {-Pr }\end{array}$ \\
\hline $\mathrm{RSO}_{2} \mathrm{H}$ & 0.8 indole, $1 \mathrm{TBAI}, 0.3 \mathrm{TsOH}, 110 \mathrm{~W}, 70^{\circ} \mathrm{C}^{[13]}$ & Me, $n$-Oct \\
\hline \multirow[t]{2}{*}{$\mathrm{RSO}_{2} \mathrm{Na}$} & $\begin{array}{c}0.8 \text { indole, } 8 \% \mathrm{I}_{2}, 2 \mathrm{H}_{2} \mathrm{O}_{2}, 2.6 \text { diethylphosphite, } \mathrm{PEG}_{400}, 100 \mathrm{~W}, 70^{\circ} \mathrm{C}^{[10 \mathrm{c}]} \\
0.5 \text { indole, } 5 \% \mathrm{I}_{2}, 1.5 \mathrm{DMSO}, 1 \text { diethylphosphite, } 100^{\circ} \mathrm{C} \text {, anisole under } \\
\operatorname{argon}^{[10 \mathrm{~d}]}\end{array}$ & $\mathrm{Me}$ \\
\hline & & $\mathrm{Me}, \mathrm{Et}, \mathrm{Pr}$ \\
\hline RS-SR & 1 indole, $5 \% \mathrm{I}_{2}, 3 \mathrm{DMSO}, 100 \mathrm{~W}, 80^{\circ} \mathrm{C}^{[9]}$ & Et, Bn \\
\hline $\mathrm{RSO}_{2} \mathrm{SR}$ & 1.2 indole, $120^{\circ} \mathrm{C}, \mathrm{H}_{2} \mathrm{O}$ under $\operatorname{argon}^{[8 \mathrm{a}]}$ & $\mathrm{Me}$ \\
\hline
\end{tabular}

Table 2. Conversions ${ }^{\perp}$ of $\mathbf{Q S O}_{2}$ SEt (determined by ${ }^{1} \mathrm{H}$ NMR) when reacted with stoichiometric amounts of indole and of various Lewis acids (0.2 $\mathrm{M}$ in dichloromethane, room temperature, $18 \mathrm{~h})$.

\begin{tabular}{cc}
\hline Lewis acid & Conversion $(\%)$ \\
\hline $\mathrm{NiCl} 2$ & 10 \\
\hline $\mathrm{CoCl} 2$ & 15 \\
\hline $\mathrm{CuCl} 2$ & 35 \\
\hline $\mathrm{MgCl} 2$ & 0 \\
\hline $\mathrm{ZnCl} 2.6 \mathrm{H} 2 \mathrm{O}$ & $>90$ \\
\hline
\end{tabular}

Two features are indicative of the transformation of the starting materials into the expected 3-(ethylthio)indole as illustrated in Figure 1: i) the disappearance of the signal at $6.34 \mathrm{ppm}$, corresponding to the proton at the 3-indole position (green), and ii) the appearance of a new quadruplet at $2.65 \mathrm{ppm}$, corresponding to the new $3-\mathrm{S}-\mathrm{CH}_{2}-\mathrm{CH}_{3}$ moiety (orange), at the expense the corresponding protons in the starting QSO2SEt (3.29 ppm, blue). Protons from the quinoline moiety also disappear due to the formation of an insoluble adduct with the Lewis acid. The thiosulfonate was consumed within 3 hours, and no trace of the possible 2-sulfenylated by-product was detected. The lack of reaction with other Lewis acid may be at least partially attributed to the poor solubility of most inorganic salts in the chlorinated solvent.

Figure 1. ${ }^{1} \mathrm{H}$ NMR spectrum (recorded at $500 \mathrm{MHz}$ in $\mathrm{CDCl}_{3}$ ) of the crude reaction mixture between $\mathbf{Q S O} \mathbf{O}_{2} \mathbf{S E t}$ and indole in the presence of $\mathrm{ZnCl}_{2} \cdot 6 \mathrm{H}_{2} \mathrm{O}$ in dichloromethane after 1 and 3 hours. The main peaks are labelled. 


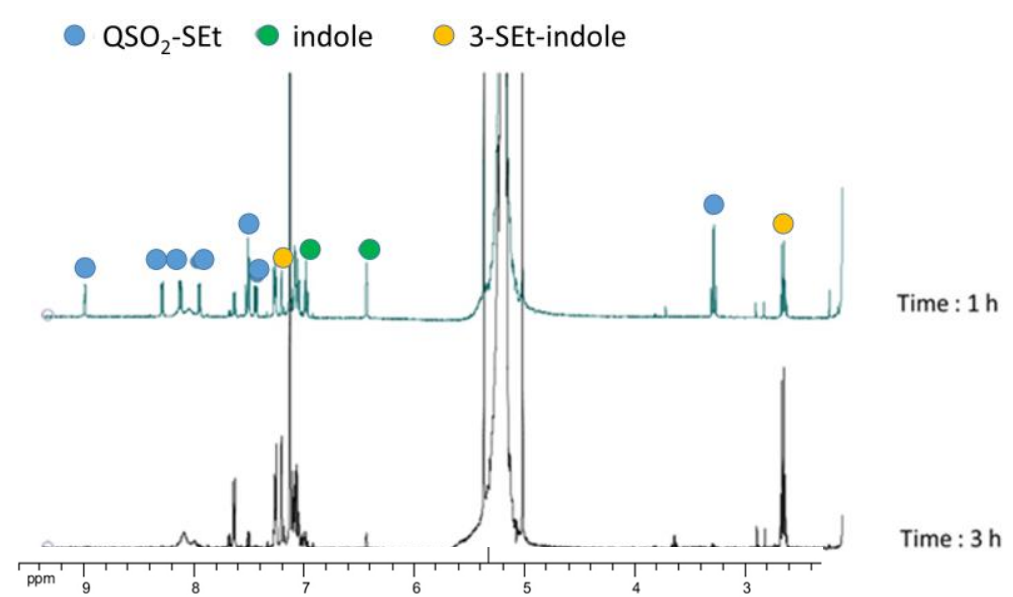

A screening of various indoles indicated that zinc chloride and $\mathbf{Q S O}_{2}^{3} \mathbf{S E t}$ in dichloromethane at room temperature efficiently convert both electron-rich (Table 3, entries b-e) and electron-deficient indoles (Table 3, entries g-i) to their 3-sulfenylated derivatives. Unsurprisingly, the reaction is faster with 5-methoxyindole than with 5-bromoindole, as shown in Figures S1-S2. For instance, after 3 hours only a 50\% conversion is recorded with the latter when the reaction is almost completed with the former. The presence of substituents at the 1- or 2- position of the indole ring does not interfere with the C3-sulfenylation (entries c, d, j), and as expected $\mathbf{Q S O}_{2} \mathbf{S E t}$ was fully recovered after reaction with 3-methylindole (entry f).

Table 3. Isolated yields recorded after reaction of various indoles ( 0.95 equiv.) with $\mathbf{Q S O} \mathbf{O}_{2} \mathbf{S E t}$ and $\mathrm{ZnCl}_{2} .6 \mathrm{H}_{2} \mathrm{O}(1.0$ equiv. each, reagents $\sim 0.2 \mathrm{M}$ in dichloromethane for $18 \mathrm{~h}$ or in ethyl acetate for $42 \mathrm{~h}$ at $\mathrm{rt}$ ).

\begin{tabular}{cccc}
\hline Exp. No. & Indole & Solvent & $\begin{array}{c}\text { Yield } \\
(\%)\end{array}$ \\
\hline $\mathrm{a}$ & Indole & $\mathrm{CH}_{2} \mathrm{Cl}_{2}$ & 88 \\
\hline $\mathrm{b}$ & 5-methylindole & $\mathrm{CH}_{2} \mathrm{Cl}_{2}$ & 84 \\
\hline $\mathrm{c}$ & 2-methylindole & $\mathrm{CH}_{2} \mathrm{Cl}_{2}$ & 89 \\
\hline $\mathrm{d}$ & 1-methylindole & $\mathrm{CH}_{2} \mathrm{Cl}_{2}$ & 85 \\
\hline $\mathrm{e}$ & 5-methoxyindole & $\mathrm{CH}_{2} \mathrm{Cl}_{2}$ & 81 \\
\hline $\mathrm{f}$ & 3-methylindole & $\mathrm{CH}_{2} \mathrm{Cl}_{2}$ & 0 \\
\hline $\mathrm{g}$ & 5-fluoroindole & $\mathrm{CH}_{2} \mathrm{Cl}_{2}$ & 78 \\
\hline $\mathrm{h}$ & 5- chloroindole & $\mathrm{CH}_{2} \mathrm{Cl}_{2}$ & 83 \\
\hline $\mathrm{i}$ & 6-bromoindole & $\mathrm{CH}_{2} \mathrm{Cl}_{2}$ & 76 \\
\hline $\mathrm{j}$ & 2-methyl-5-bromoindole & $\mathrm{CH}_{2} \mathrm{Cl}_{2}$ & 91 \\
\hline $\mathrm{k}$ & 5-hydroxyindole & $\mathrm{EtOAc}$ & 79 \\
\hline
\end{tabular}

Interestingly, the reaction also proceeds smoothly at room temperature in ethyl acetate, although at slower rate than in dichloromethane. Thus, the full conversion of indole to 3-(ethylthio)indole requires 42 hours in ethyl acetate, while the reaction was complete after $3 \mathrm{~h}$ in dichloromethane. However, this allowed for the use of substrates insoluble in dichloromethane, such as 5 -hydroxyindole (entry k). The reaction is not catalytic, indicating that the Lewis acid remains coordinated to the quinoline moiety after the sulfenyl transfer. A tentative mechanism is proposed in Scheme S1.

Table 4. Yields obtained after reaction of 5-methylindole with 1.05 equiv. of various thiosulfonates and $\mathrm{ZnCl}_{2} .6 \mathrm{H}_{2} \mathrm{O}(1.0$ equiv. each, reagents $\sim 0.2 \mathrm{M}$ in dichloromethane for $18 \mathrm{~h}$ at $\mathrm{rt}$ ). 


\begin{tabular}{cc}
\hline Thiosulfonate & Yield (\%) \\
\hline $\mathrm{QSO}_{2} \mathrm{SBn}$ & 81 \\
\hline $\mathrm{QSO}_{2}$ SAllyl & 91 \\
\hline $\mathrm{QSO}_{2}$ SCys & 48 \\
\hline $\mathrm{QSO}_{2}$ SPropyne & 83 \\
\hline $\mathrm{QSO}_{2} \mathrm{SBuEt}$ & 85 \\
\hline $\mathrm{QSO}_{2} \mathrm{SPrCN}$ & 89 \\
\hline $\mathrm{QSO}_{2} \mathrm{SPh}$ & 79 \\
\hline
\end{tabular}

Finally, we investigated the sulfenylation of 5-methylindole with various thiosulfonates, easily obtained by the reaction between the 8-quinolinethiosulfonate pyridinium salt and primary alkyl bromides. ${ }^{[7]}$ We were however unable to obtain thiosulfonates from secondary alkyl halides, despite the previous preparation of phenylthiosulfonates using this synthetic strategy. $\stackrel{\left[?,{ }^{14]}\right.}{ }$ As reported in Table 4, good yields of 5-methylindole were observed, even with the more functionalized substrate $\mathbf{Q S O}_{2} \mathbf{S C y s}$. The reaction is not limited to alkylthiosulfonates, and although this methodology may not be the most appropriate to introduce -S(aryl) groups, 3-(phenylthio)-5-methylindole was cleanly formed from indole and $\mathbf{Q S O}_{2} \mathbf{S P h}$.

In conclusion, I propose a new tool to efficiently introduce alkylsulfenyl moieties at the C3-position of indoles under mild conditions. The extension of this methodology to other activated $\mathrm{C}-\mathrm{H}$ bonds is currently under study.

\section{Acknowledgments}

EG thanks I. Martin for her help, and Pr. H. Dhimane (UMR 8601) for useful discussions.

\section{References and notes}

${ }^{\perp}$ Conversions are rounded to the nearest $5 \%$ and determined by ${ }^{1} \mathrm{H}$ NMR. Abbreviations: TBAI: tetrabutylammonium iodide, DMSO: dimethylsulfoxide, TsOH: para-toluenesulfonic acid

[1] a) H. Mutlu, E. B. Ceper, X. Li, J. Yang, W. Dong, M. M. Ozmen, P. Theato, Macromol. Rapid Comm. 2019, 40, e1800650; b) M. J. H. Worthington, R. L. Kucera, J. M. Chalker, Green Chem. 2017, 19, 2748-2761.

[2] M. H. Feng, B. Q. Tang, S. H. Liang, X. F. Jiang, Curr .Top. Med. Chem. 2016, 16, 1200-1216.

[3] a) P. Bichler, J. A. Love, Top. Organomet. Chem. 2010, 31, 39-64; b) P. Chauhan, S. Mahajan, D. Enders, Chem. Rev. 2014, 114, 8807-8864; c) T. Kondo, T. A. Mitsudo Ta, Chem. Rev. 2000, 100, 3205-3220; d) X. D. Li, Y. T. Gao, Y. J. Sun, X. Y. Jin, D. Wang, L. Liu, L. Cheng, Org. Lett. 2019, 21, 6643-6647; e) K. Tanimoto, R. Ohkado, H. Iida, J. Org. Chem. 2019, 54, 14980; f) Q.-H. Teng, Y. Yao, W.-X. Wei, H.-T. Tang, J.-R. Li, Y.-M. Pan, Green Chem 2019, $21,6241$. [4] a) D. Q. Dong, S. H. Hao, D. S. Yang, L. X. Li, Z. L. Wang, Eur. J. Org. Chem. 2017, 6576-6592; b) C. Shen, P. F. Zhang, Q. Sun, S. Q. Bai, T. S. A. Hor, X. G. Liu, Chem. Soc. Rev. 2015, 44, 291-314.

[5] a) N. K. Kaushik, N. Kaushik, P. Attri, N. Kumar, C. H. Kim, A. K. Verma, E. H. Choi, Molecules 2013, 18, 66206662; b) K. N. Pham, A. Lewis-Ballester, S. R. Yeh, J. Am. Chem. Soc. 2019, 141, 18771; c) T. V. Sravanthi, S. L. Manju, Eur. J. Pharm. Sci. 2016, 91, 1-10.

[6] a) M. Tudge, M. Tamiya, C. Savarin, G. R. Humphrey, Org. Lett. 2006, 8, 565-568; b) D. Equbal, R. Singh, Saima, A. G. Lavekar, A. K. Sinha, J. Org. Chem. 2019, 84, 2660-2675; c) A. Hosseinian, S. Arshadi, S. Sarhandi, A. Monfared, E. Vessally, J.Sulfur Chem. 2019, 40, 289-311.

[7] P. Mampuys, C. R. McElroy, J. H. Clark, R. V. A. Orru, B. U. W. Maes, Adv. Synth. Catal. 2020, 362, 3-64. 
[8] a) C. Ravi, A. Joshi, S. Adimurthy, Eur. J. Org. Chem. 2017, 2017, 3646-3651; b) T. T. Song, H. Y. Li, F. Wei, C. H. Tung, Z. H. Xu, Tetrahedron Lett. 2019, 60, 916-919; c) R. J. Reddy, A. H. Kumari, J. J. Kumar, J. B. Nanubolu, Adv. Synth. Catal. 2019, 361, 1587-1591.

[9] J. B. Azeredo, M. Godoi, G. M. Martins, C. C. Silveira, A. L. Braga, J. Org. Chem. 2014, 79, 4125-4130.

[10]a) P. P. Kumar, Y. D. Reddy, C. V. R. Reddy, B. R. Devi, P. K. Dubey, J. Sulfur $\quad$ Chem. 2014, 35, 356-361; b) Y. Z. He, J. Jiang, W. H. Bao, W. Deng, J. N. Xiang, Tetrahedron Lett. 2017, 58, 4583-4586; c) R. Rahaman, P. Barman, Eur. J. Org. Chem. 2017, 6327-6334; d) F. H. Xiao, H. Xie, S. W. Liu, G. J. Deng, Adv. Synth. Catal. 2014, 356, 364368; e) X. Q. Yang, Y. S. Bao, Z. H. Dai, Q. F. Zhou, F. L. Yang, Green Chem. 2018, 20, 3727-3731.

[11]W. L. Ge, Y. Y. Wei, Synthesis 2012, 44, 934-940.

[12]G. Kumaraswamy, R. Raju, V. Narayanarao, RSC Adv. 2015, 5, 22718-22723.

[13]R. Rahaman, N. Devi, J. R. Bhagawati, P. Barman, RSC Adv. 2016, 6, 18929-18935.

[14]D. P. Gamblin, P. Garnier, S. J. Ward, N. J. Oldham, A. J. Fairbanks, B. G. Davis, Org. Biomol. Chem. 2003, 1, 36423644.

\section{Supplementary Material}

Experimental data and raw NMR data. 